Check for updates

Cite this: RSC Adv., 2017, 7, 46925

\title{
Synthesis and characterization of cobalt hydroxide carbonate nanostructures
}

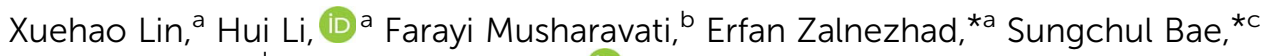 \\ Bum-Yean $\mathrm{Cho}^{\mathrm{d}}$ and Oscar K. S. Hui (iD e
}

Battery-type electrodes of three-dimensional (3D) hierarchical cobalt hydroxide carbonate arrays on $\mathrm{Ni}$ foam were fabricated using a hydrothermal method for use in supercapacitors. X-ray diffraction analysis, scanning electron microscopy, and transmission electron microscopy were used to characterize their structures and morphologies. The cobalt hydroxide carbonate synthesized with $10 \mathrm{~h}$ reaction time showed the highest specific capacitance ( $1381 \mathrm{~F} \mathrm{~g}^{-1}$ at a current density of $2 \mathrm{~A} \mathrm{~g}^{-1}$ ) and excellent cycling stability (92\% capacitance retention after 5000 cycles). Moreover, its capacitance increased by $33 \%$ at $2 \mathrm{~A} \mathrm{~g}^{-1}$ and by $10 \%$ at $20 \mathrm{~A} \mathrm{~g}^{-1}$ after 5000 charge-discharge cycles. This cobalt hydroxide carbonate composite is a promising candidate for electrochemical energy-related applications.

Received 16th August 2017

Accepted 20th September 2017

DOI: 10.1039/c7ra09050a

rsc.li/rsc-advances and conducting polymers such as polypyrrole (PPY) and transition metal oxides $\left(\mathrm{MnO}_{2}, \mathrm{RuO}_{2}, \mathrm{NiO}, \mathrm{Co}_{3} \mathrm{O}_{4}\right)$, have shown excellent specific capacitance., ${ }^{6,7}$ Due to its good electrical conductivity and multiple redox states, hydrous ruthenium dioxide $\left(\mathrm{RuO}_{2}\right)$ has been assumed to be the most promising electrode material among the transition metal oxides. ${ }^{8}$ However, the toxicity and high cost of this noble metal are considerable obstacles for real applications. ${ }^{2,9,10}$ Hence, more work has been dedicated to other environmentally friendly and cheap inexpensive electrode materials. Cobalt hydroxide and its derivatives have attracted much attention as possible FS electrode materials because of their good electrochemical stability and high theoretical capacitance. ${ }^{11}$ Nonetheless, based on the literature, the theoretical value of $\mathrm{Co}(\mathrm{OH})_{2}$ is much higher than its specific capacity. Therefore, remarkable efforts have been concentrated on developing the electrochemical performance of $\mathrm{Co}(\mathrm{OH})_{2}$ by combining carbon materials and controlling morphology. ${ }^{12}$

In this study, a one-step approach was applied to grow cobalt hydroxide carbonate directly on $\mathrm{Ni}$ foam $\left(\mathrm{Co}(\mathrm{OH})_{2}\left(\mathrm{CO}_{3}\right)_{0.5} / \mathrm{NF}\right)$ using a hydrothermal technique conducted at $95{ }^{\circ} \mathrm{C}$, with various synthesis times of 6,10 , and $14 \mathrm{~h}$. The electrochemical capacitive performance of the cobalt hydroxide carbonates formed after the various reaction times was examined using electrochemical impedance spectroscopy (EIS), galvanostatic charge-discharge (GCD) measurements, and cyclic voltammetry (CV).

\section{Experimental details}

All chemicals were of analytical grade and were used as received. $\mathrm{Co}\left(\mathrm{No}_{3}\right)_{2} \cdot 6 \mathrm{H}_{2} \mathrm{O}$, urea, and $\mathrm{HCl}$ were purchased from Samchun (Korea). Nickel foam was purchased from Yierda (China). 


\subsection{Synthesis}

Prior to the hydrothermal process, nickel foam was sonicated in $1 \mathrm{M} \mathrm{HCl}$ solution for $20 \mathrm{~min}$ in order to remove any existing $\mathrm{NiO}$ film on the surface of the foam. This was followed by rinsing with absolute ethanol and distilled water several times. Finally, the Ni foam was desiccated overnight in an air oven at $60{ }^{\circ} \mathrm{C}$.

To synthesize cobalt hydroxide carbonate, urea $(1.32 \mathrm{~g})$ and $\mathrm{Co}\left(\mathrm{No}_{3}\right)_{2} \cdot 6 \mathrm{H}_{2} \mathrm{O}(1.2 \mathrm{~g})$ were added to $45 \mathrm{~mL}$ of deionized water and stirred for $20 \mathrm{~min}$. The mixture was then transferred to a $100 \mathrm{~mL}$ Teflon-lined stainless steel autoclave holding 4 pieces of nickel foam $\left(1 \mathrm{~cm}^{2}\right)$ and then held at $95{ }^{\circ} \mathrm{C}$ for the growth time of 6,10 , or $14 \mathrm{~h}$; the resulting products are abbreviated $\mathrm{CCH}-6, \mathrm{CCH}-10$, and $\mathrm{CCH}-14$, respectively. Once the autoclave cooled to ambient temperature, the pale pink product was rinsed with distilled water several times and dried overnight in an oven at $60{ }^{\circ} \mathrm{C}$. Normally, urea will decompose into carbon oxide and ammonia when the temperature rises to $80{ }^{\circ} \mathrm{C}$. Therefore, the formation of cobalt hydroxide carbonate included hydrolysis precipitation, whereby the urea continuously provided both hydroxyl and carbonate anions to generate cobalt hydroxide carbonate on the nickel foam.

The decomposition of urea can be expressed as follows:

$$
\begin{gathered}
\mathrm{H}_{2} \mathrm{NCONH}_{2}+\mathrm{H}_{2} \mathrm{O} \rightarrow 2 \mathrm{NH}_{3}+\mathrm{CO}_{2} \\
\mathrm{CO}_{2}+\mathrm{H}_{2} \mathrm{O} \rightarrow \mathrm{CO}_{3}^{2-}+2 \mathrm{H}^{+} \\
\mathrm{NH}_{3}+\mathrm{H}_{2} \mathrm{O} \rightarrow \mathrm{NH}_{4}^{+}+\mathrm{OH}^{-}
\end{gathered}
$$

The formation of cobalt hydroxide carbonate can be expressed as follows:

$$
2 \mathrm{Co}^{2+}+2 \mathrm{OH}^{-}+\mathrm{CO}_{3}^{2-} \leftrightarrow \mathrm{Co}_{2}(\mathrm{OH})_{2} \mathrm{CO}_{3}
$$

\subsection{Electrochemical characterization}

A conventional three-electrode electrochemical cell in an electrochemical workstation ( $\mathrm{sp} 2$, Zive) was applied to characterize the electrochemical properties of the electrode. Cycle stability measurements were conducted at $40 \mathrm{~A} \mathrm{~g}^{-1}$ for 5000 cycles. CV experiments were executed in the range of -0.1 to $0.6 \mathrm{~V}$ ( $v s$. SCE) at various scan rates. The potential of $0.5 \mathrm{~V}$ ( $v s$. SCE) at different current densities was adjusted for measuring the GCD curves. EIS measurements were performed over the frequency range of $100 \mathrm{kHz}$ to $0.01 \mathrm{~Hz}$ at the open circuit potential with a $5 \mathrm{mV} \mathrm{AC}$ perturbation. The cobalt hydroxide carbonate served as the working electrode. A $\mathrm{HgO}$ electrode filled with $6 \mathrm{M} \mathrm{KOH}$ and a platinum electrode were respectively used as the reference and counter electrodes. A $6 \mathrm{M}$ aqueous solution of $\mathrm{KOH}$ was used as the electrolyte.

\subsection{Characterizations}

The structural and morphological properties of the specimens were characterized using field emission scanning electron microscopy (FESEM, LEO-1550) with an applied voltage of $5 \mathrm{kV}$.
X-ray diffraction (XRD, Bruker D8 Advance X-ray) analysis of the specimens was carried out under $\mathrm{Cu} K \alpha$ radiation $(\lambda=0.15406 \mathrm{~nm})$ at $40 \mathrm{kV}$ and $30 \mathrm{~mA}$. The scanning speed was $5^{\circ} \min ^{-1}$ with $0.02^{\circ}$ steps.

\section{Results and discussion}

For fabrication of the electrode, the conventional hydrothermal method was used; this process includes transportation of metal ions to the nickel foam surface, adsorption and enrichment of ions, and nucleation and growth of cobalt hydroxide carbonate crystals. ${ }^{13}$ Through the hydrothermal process, the metal ions reacted with $\mathrm{CO}_{3}{ }^{2-}$ and $\mathrm{OH}^{-}$(decomposed from urea) to create cobalt hydroxide carbonate particles that grew directly on the nickel foam surface. ${ }^{14}$ The successful preparation of $\mathrm{Co}(\mathrm{OH})_{2}\left(\mathrm{CO}_{3}\right)_{0.5}$ on nickel foam was confirmed using XRD. To exclude strong XRD peak signals of the Ni foam substrate, the cobalt hydroxide carbonate powder alone was subjected to XRD. Fig. 1 shows the XRD patterns of $\mathrm{CCH}-6$ and $\mathrm{CCH}-10$. However, XRD patterns of the samples showed an additional peak, attributed to a $\mathrm{Co}(\mathrm{OH})_{2}$ phase formed from $\mathrm{OH}^{-}$and $\mathrm{Co}^{2+}$ during the hydrothermal reaction.

The morphology of a supercapacitor electrode material significantly influences its capacitance and cycling stability. ${ }^{\mathbf{1 5}}$ The porous 3D network structure of nickel foam provides much area that form the unique structure and ion channel. ${ }^{16}$ Fig. $2 \mathrm{a}-\mathrm{c}$ shows the morphology of $\mathrm{CCH}-6$, clearly illustrating that the active material formed atop the substrate was comprised mainly of nanowires. The $\mathrm{Co}(\mathrm{OH})_{2}\left(\mathrm{CO}_{3}\right)_{0.5}$ was uniformly arranged on the surface of the nickel foam, which is good for delivering electrons during the charging and discharging processes. ${ }^{\mathbf{1 7}}$ Abundant open space and a rich electroactive surface can be generated by the dense nanowires. The presence of nanowires perpendicular to the surface and that are directly appended to the current collector avoids the need for binders and considerably decreases the "dead volume" in the electrode. ${ }^{18}$ The free space between nanowires is favorable for electrolyte diffusion into the electrode, reducing the hydroxide ion diffusion length. For the reaction time of $10 \mathrm{~h}$, the nanowires tended to form

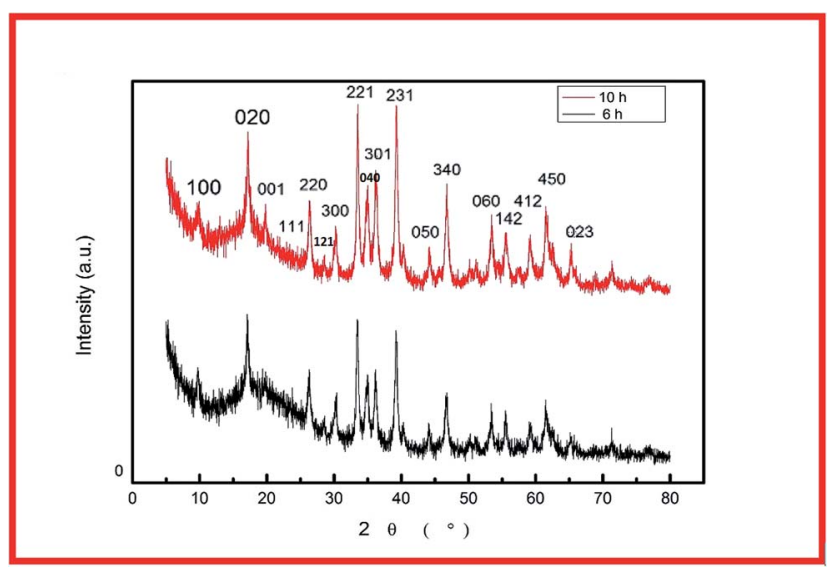

Fig. 1 XRD patterns of $\mathrm{CCH}-6$ and $\mathrm{CCH}-10$. 

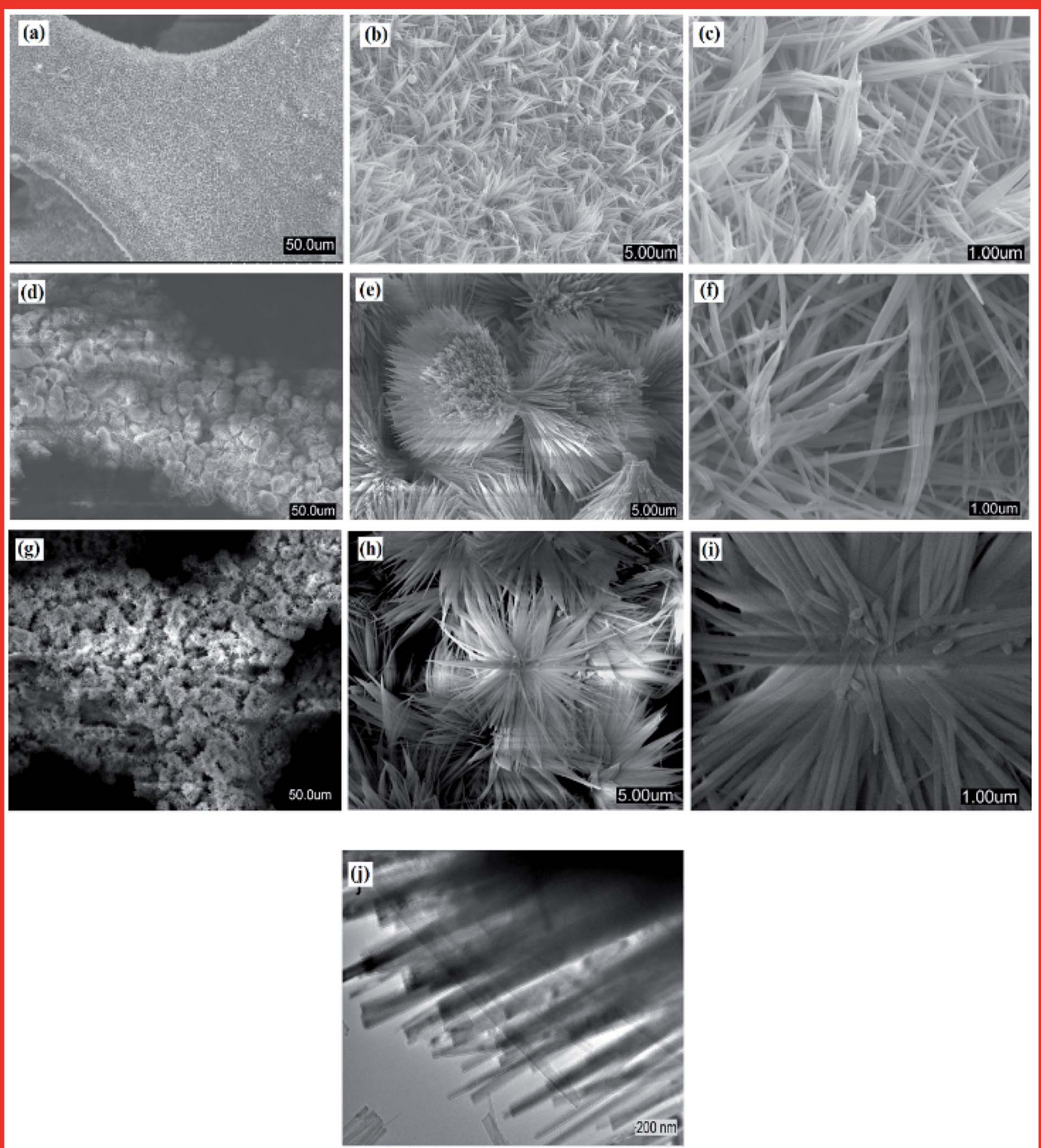

Fig. 2 SEM images of $(a-c) C C H-6$, (d-f) $\mathrm{CCH}-10$, and (g-i) $\mathrm{CCH}-14$; (j) TEM image of $\mathrm{CCH}-10$.

acicular bundles several microns in size that were uniformly distributed over the sample (see Fig. 2d-f). Such acicular bundles offer many active points for redox reactions of the active material and enhance the surface contact between the electrolyte and the active material to improve the cycling stability and specific capacitance. After $14 \mathrm{~h}$ of hydrothermal reaction, the nanowires agglomerated into leaf-like structures, vastly decreasing the total surface area of the electrode material and thereby reducing its capacitance.
The specimens were characterized by CV, GCD, and EIS to explore the electrochemical properties of the cobalt hydroxide carbonates prepared using various reaction times. Fig. 3a-f presents the $\mathrm{CV}$ and $\mathrm{CD}$ curves of cobalt hydroxide carbonate. $\mathrm{CV}$ analysis of these materials as electrodes was carried out at various scan rates from 5 to $50 \mathrm{mV} \mathrm{s}^{-1}$ in $6 \mathrm{M} \mathrm{KOH}$ solution over the range of -0.1 to $0.6 \mathrm{~V}(v s$. $\mathrm{HgO})$. A pair of redox peaks was clearly evident in each $\mathrm{CV}$ trace, representing the typical faradaic behavior of battery-type electrodes. ${ }^{19}$ The peaks arise from 

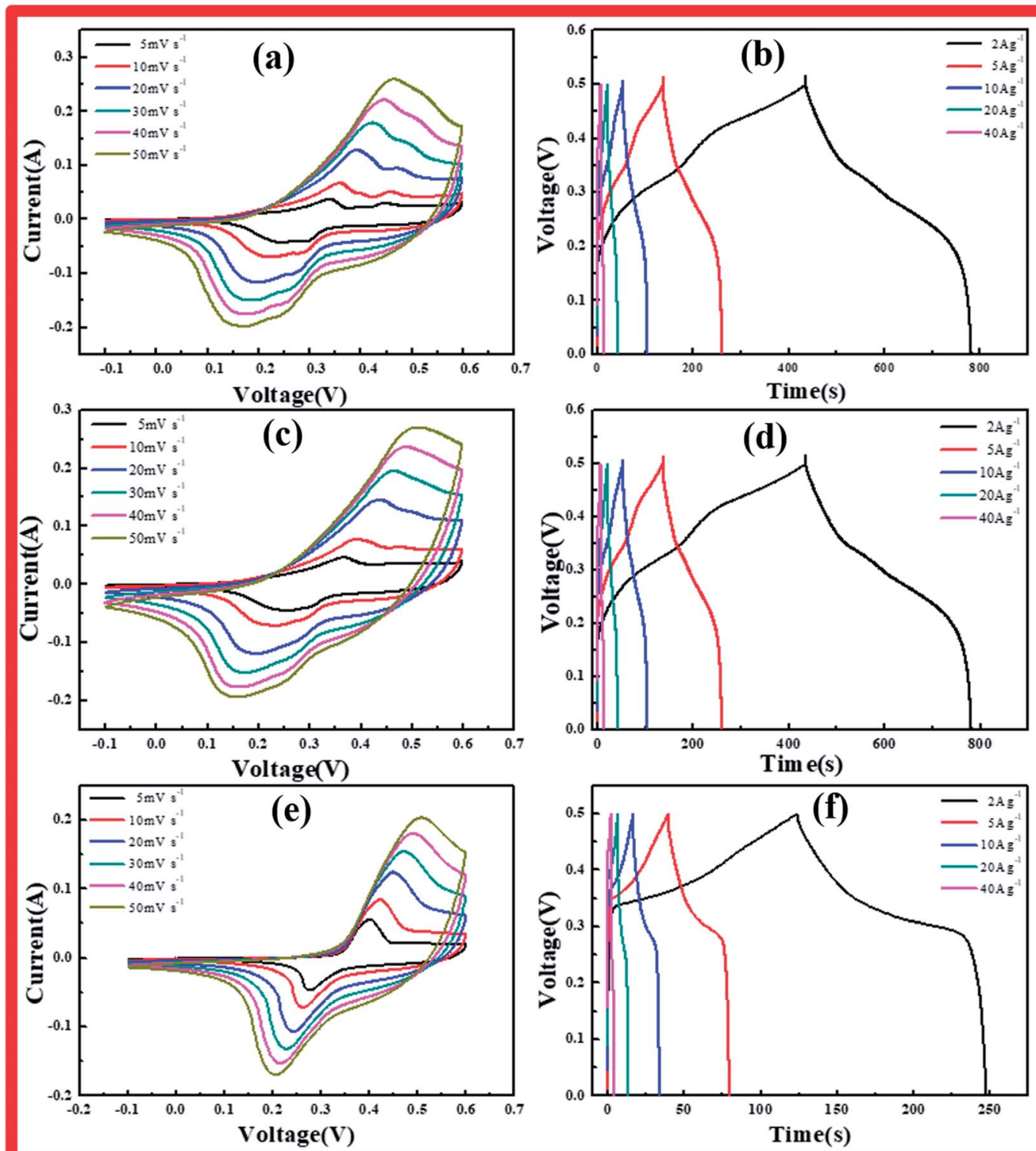

Fig. 3 (a, c, e) CV curves collected at scan rates from 5 to $50 \mathrm{mV} \mathrm{s}^{-1}$ in $6 \mathrm{M} \mathrm{KOH}$ electrolyte, and (b, d, f) CD curves of cobalt hydroxide carbonate collected under various current densities from 2 to $40 \mathrm{~A} \mathrm{~g}^{-1}$ for cobalt hydroxide carbonate samples prepared using various reaction times: (a, b) $\mathrm{CCH}-6$, (c, d) $\mathrm{CCH}-10$, (e, f) $\mathrm{CCH}-14$.

the faradaic redox process of $\mathrm{Co}^{2+} / \mathrm{Co}^{3+}$ based on the following reactions:

$$
\begin{gathered}
\mathrm{Co}(\mathrm{OH})_{2}+\mathrm{OH}^{-} \rightarrow \mathrm{CoOOH}+\mathrm{H}_{2} \mathrm{O}+\mathrm{e}^{-} \\
\mathrm{CoOOH}+\mathrm{OH}^{-} \rightarrow \mathrm{CoO}_{2}+\mathrm{H}_{2} \mathrm{O}+\mathrm{e}^{-}
\end{gathered}
$$

The cathodic and anodic peaks in the CV curves shifted toward negative and positive potential, respectively, with increasing scan rate, continuously increasing the potential difference between the reduction and oxidation peaks, indicating the redox couple's quasi-reversible feature. This phenomenon arose from the increasing polarization of the electrode and ohmic resistance during the redox reaction at higher scan rates when the electrolyte ions diffused in the porous electrode. ${ }^{20}$

The $\mathrm{Co}(\mathrm{OH})_{2}\left(\mathrm{CO}_{3}\right)_{0.5} / \mathrm{NF}$ electrode charge-discharge curves were collected under various current densities. The shapes of these curves showed mostly pseudocapacitance behavior, in agreement with the $\mathrm{CV}$ results. $\mathrm{CCH}-14$ showed a standard battery-type curve due to its unique structure, which supplied broad channels for ion diffusion, unlike CCH-6 and CCH-10. The specific capacitance of each $\mathrm{Co}(\mathrm{OH})_{2}\left(\mathrm{CO}_{3}\right)_{0.5} / \mathrm{NF}$ sample was calculated from these curves according to the following equation:

$$
C=(I / \Delta t) /(m / \Delta v)
$$


where $I$ is the discharge current, $\Delta t$ is the time, $\Delta V$ is the potential range, and $m$ is the mass of active material on the working electrode.

The specific capacitances of $\mathrm{CCH}-10$ were calculated to be $1381,1226,1006,827$, and $525 \mathrm{~F} \mathrm{~g}^{-1}$ at scan rates of $2,5,10,20$, and $40 \mathrm{~A} \mathrm{~g}^{-1}$, respectively. For $\mathrm{CCH}-6$, the specific capacitances were much higher: $1548,1324,1129,951$, and $583 \mathrm{~F} \mathrm{~g}^{-1}$ at scan rates of $2,5,10,20$, and $40 \mathrm{~A} \mathrm{~g}^{-1}$, respectively. CCH- 6 better capacitance because of its structure of vertically oriented nanowires distributed on the nickel foam surface, which provided many more active sites to react with the electrolyte during the initial charge-discharge cycle. In this structure, almost all of the electrode's active surface area is in good contact with the electrolyte ions, allowing full reaction at low current densities, which leads to high capacitance. The capacitance drop observed with increasing scan rate might have arisen from a pore diffusion limitation. ${ }^{21}$

EIS analysis was conducted to examine the electrodes' fundamental behavior (Fig. 4). This analysis was performed over the frequency range of $100 \mathrm{kHz}$ to $0.01 \mathrm{~Hz}$. The curves of the three samples each showed a depressed arc in the high frequency region and an inclined line in the low frequency region. ${ }^{21,22}$ The curve intercept at the real axis $\left(Z^{\prime}\right)$ is equal to the internal resistance $\left(R_{\mathrm{S}}\right)$ in the high frequency region, which represents the sum of the contact resistance, the electrolyte, and the ohmic resistance of the active materials at the interface between the active materials and the current collector. These EIS results indicate that the three samples had nearly the same internal resistance. In the middle frequency region, a semicircular feature in each curve (corresponding to the charge transfer resistance $R_{\mathrm{ct}}$ ) represents the charge transfer process at the interface between the working electrode and the electrolyte.
The charge transfer resistance is related to the electrode's electroactive surface area electroactive area leading to lower charge transfer resistance. The EIS results suggest that the specimen structure of the nanowire form yielded better charge transfer between the electrolyte and electrode. The structure of acicular bundles exhibited relatively high charge transfer resistance because the bundles hindered charge transfer. The Warburg impedance $(W)$ was obtained from the curve slope of the low frequency region; $W$ is determined by the diffusion of electrolyte in the porous electrode and the diffusion of protons in the materials. ${ }^{23}$

High cycle stability of electrodes is an important factor in their application in energy storage devices. ${ }^{24}$ Accordingly, the electrode materials were tested for 5000 charge/discharge cycles at a current density of $40 \mathrm{Ag}^{-1}$ (Fig. 5a) CCH-5(a). For the cobalt hydroxide carbonate with 10 showed capacitance retention of 92.5\% after 5000 charge/discharge cycles. Interestingly, the capacitance of this electrode at low current density increased fast after the 5000 -cycle test $\left(1877 \mathrm{~F} \mathrm{~g}^{-1}\right.$ at $2 \mathrm{~A} \mathrm{~g}^{-1}, 1465 \mathrm{~F} \mathrm{~g}^{-1}$ at $5 \mathrm{~A} \mathrm{~g}^{-1}, 1183 \mathrm{~F} \mathrm{~g}^{-1}$ at $10 \mathrm{~A} \mathrm{~g}^{-1}$ and $880 \mathrm{~F} \mathrm{~g}^{-1}$ at $20 \mathrm{~A} \mathrm{~g}^{-1}$ ). Compared with $\mathrm{CCH}-10$, the $\mathrm{CCH}-6$ electrode exhibited poorer stability. Its specific capacity decreased from an initial value of $583 \mathrm{~F} \mathrm{~g}^{-1}$ to $238 \mathrm{~F} \mathrm{~g}^{-1}$ during the 5000 -cycle test (Fig. 5b). The CCH-14 electrode had both poor capacitance and poor cycle stability. The specific capacitance increase observed for $\mathrm{CCH}-10$ might have been caused by the intrinsic property of cobalt carbonate hydroxide, which is that the cobalt carbonate can partly dissolve in water depending on its structure and the temperature. The robustness of the $\mathrm{CCH}-10$ electrode will decrease during the charging and discharging process. Some of the aggregation partly dissolved in the water, allowing easy access of diffused ions to the structure and reaction with the

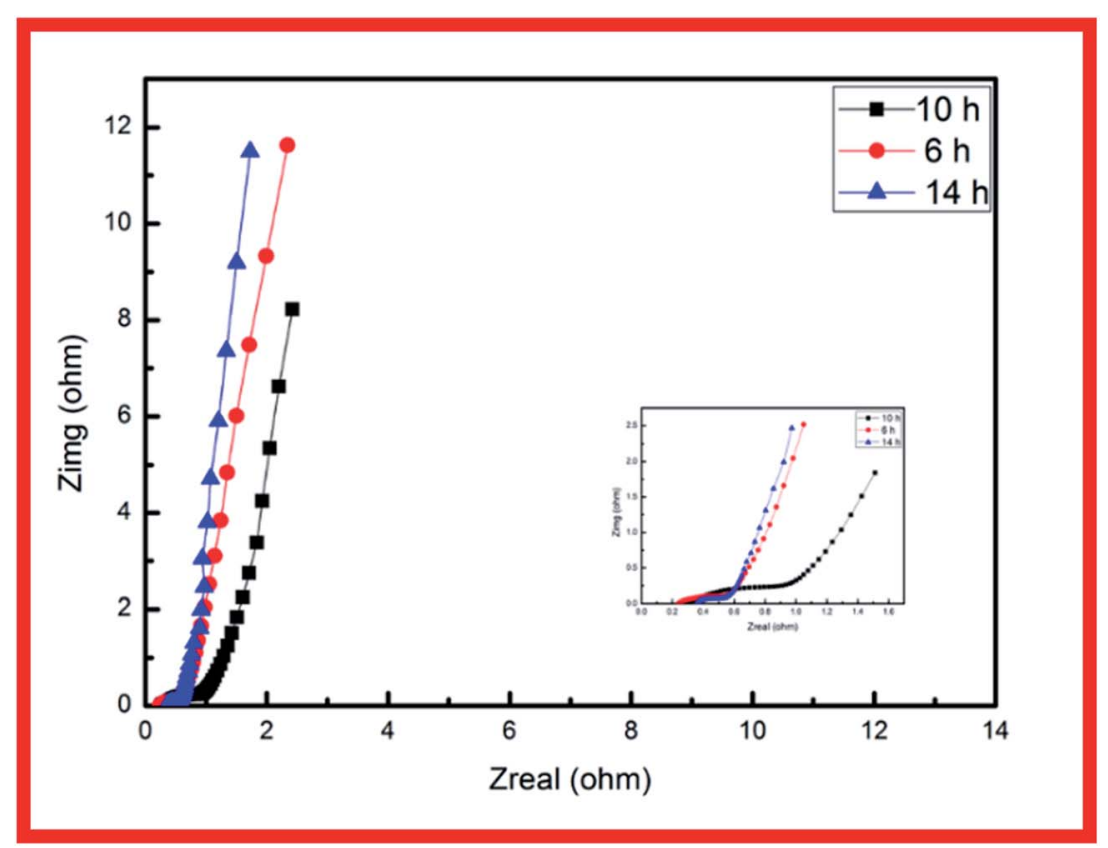

Fig. 4 Nyquist impedance plots of $\mathrm{CCH}-6, \mathrm{CCH}-10$, and $\mathrm{CCH}-14$. 

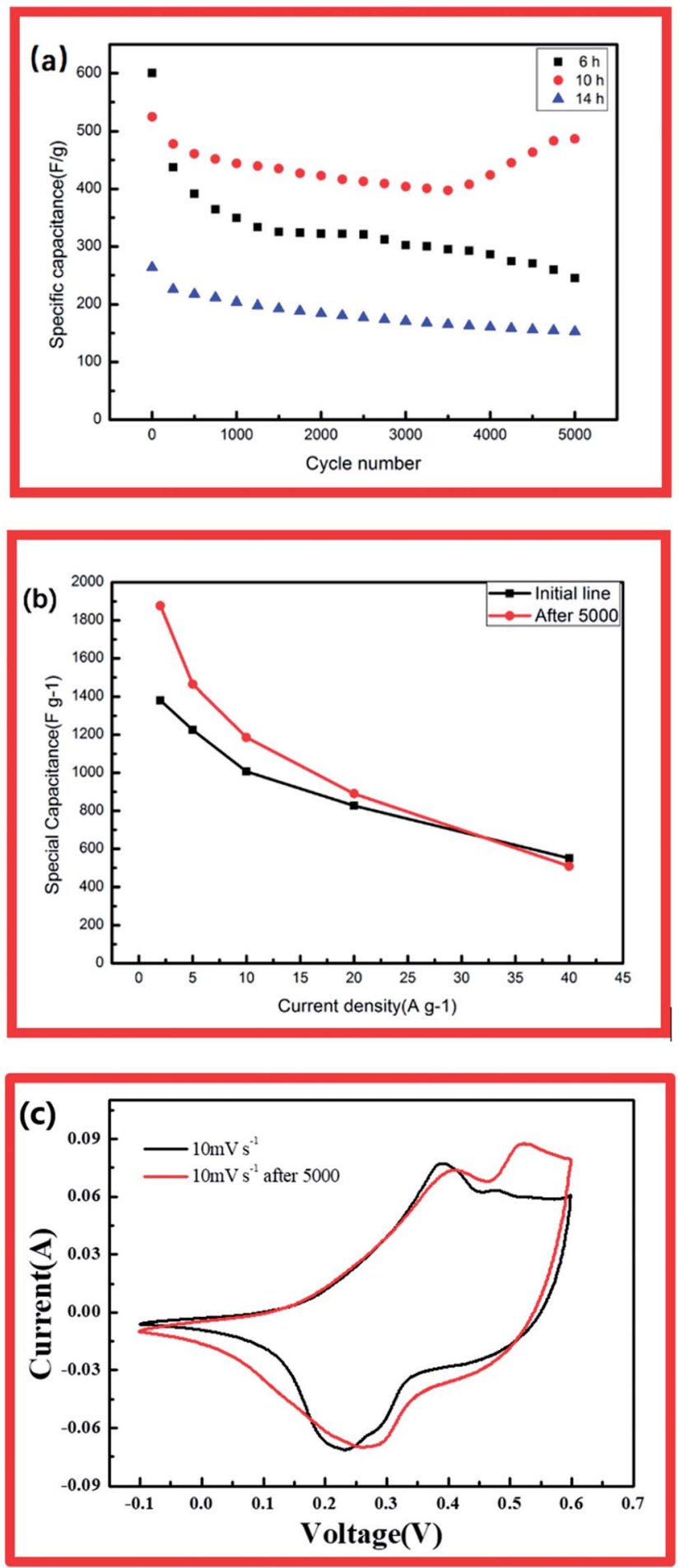

Fig. 5 (a) Cycling stabilities of $\mathrm{CCH}-6, \mathrm{CCH}-10$, and $\mathrm{CCH}-14$. (b) Specific capacitance of $\mathrm{CCH}-10$ before and after a 5000 -cycle test. (c) $\mathrm{CV}$ curves of $\mathrm{CCH}-10$ acquired before and after a 5000-cycle test.

active material. ${ }^{25}$ Fig. 5c shows $\mathrm{CV}$ curves of $\mathrm{CCH}-10$ acquired before and after the 5000-cycle test, displaying its greater capacitance after the test. This might have been caused by the increase in surface area available to react with the electrolyte when the aggregation partly dissolved in the water.

\section{Conclusions}

In the present work $\mathrm{Co}(\mathrm{OH})_{2}\left(\mathrm{CO}_{3}\right)_{0.5}$ arrays were directly grown on nickel foam by a simple hydrothermal method. The effect of reaction time on the supercapacitive performance of the resulting material was investigated. The morphology of the product could be controlled by tuning the growth time. $\mathrm{CCH}-6$ and $\mathrm{CCH}-14$ exhibited poor cycle stability, whereas $\mathrm{CCH}-10$ had a unique high-surface-area structure of acicular bundles that allowed it to achieve higher capacitance (1381 $\mathrm{F} \mathrm{g}^{-1}$ at $2 \mathrm{~A} \mathrm{~g}^{-1}$ ) and better stability (92\% retention after 5000-cycle test at $40 \mathrm{~A} \mathrm{~g}^{-1}$ ). The CCH-10 electrode achieved better capacitance at low current density after a 5000 -cycle test $\left(1877 \mathrm{~F} \mathrm{~g}^{-1}\right.$ at $2 \mathrm{~A} \mathrm{~g}^{-1}, 1465 \mathrm{~F} \mathrm{~g}^{-1}$ at $5 \mathrm{~A} \mathrm{~g}^{-1}, 1183 \mathrm{~F} \mathrm{~g}^{-1}$ at $10 \mathrm{~A} \mathrm{~g}^{-1}$ and $880 \mathrm{~F} \mathrm{~g}^{-1}$ at $\left.20 \mathrm{~A} \mathrm{~g}^{-1}\right)$. These performance metrics suggest great potential applicability of the CCH-10 material in supercapacitors.

\section{Conflicts of interest}

There are no conflicts to declare.

\section{Acknowledgements}

This work was performed at the Thin Film Coating Laboratory, Engineering Center, Hanyang University. The work was supported financially by Hanyang University, Young Faculty Forum and by a grant (16TBIP-C111710-01) from the Technology Innovation Program funded by the Ministry of Land, Infrastructure and Transport of the Korean Government.

\section{References}

1 J. Yang, T. Lan, J. Liu, Y. Song and M. Wei, Electrochim. Acta, 2013, 105, 489-495.

2 T. M. Masikhwa, J. K. Dangbegnon, A. Bello, M. J. Madito, D. Momodu, F. Barzegar and N. Manyala, J. Phys. Chem. Solids, 2016, 94, 17-24.

3 L. L. Zhang and X. Zhao, Chem. Soc. Rev., 2009, 38, 25202531.

4 Z.-S. Wu, W. Ren, D.-W. Wang, F. Li, B. Liu and H.-M. Cheng, ACS Nano, 2010, 4, 5835-5842.

5 W. Gu and G. Yushin, WIREs Energy Environ., 2014, 3, 424473.

6 C. Guan, X. Qian, X. Wang, Y. Cao, Q. Zhang, A. Li and J. Wang, Nanotechnology, 2015, 26, 094001.

7 M.-J. Deng, C.-Z. Song, C.-C. Wang, Y.-C. Tseng, J.-M. Chen and K.-T. Lu, ACS Appl. Mater. Interfaces, 2015, 7, 9147-9156.

8 Y. Wang, J. Guo, T. Wang, J. Shao, D. Wang and Y.-W. Yang, Nanomaterials, 2015, 5, 1667-1689.

9 J. D. Tshifhiwa, M. Masikhwa, A. Bello, M. J. Madito, F. Damilola Momodu and N. Manyala, J. Phys. Chem. Solids, 2016, 94, 17-24.

10 C. Yuan, L. Yang, L. Hou, L. Shen, X. Zhang and X. W. D. Lou, Energy Environ. Sci., 2012, 5, 7883-7887.

11 P. Simon and Y. Gogotsi, Nat. Mater., 2008, 7, 845-854.

12 G. Yu, X. Xie, L. Pan, Z. Bao and Y. Cui, Nano Energy, 2013, 2, 213-234. 
13 Y. Ruan, C. Wang and J. Jiang, J. Mater. Chem. A, 2016, 4, 14509-14538.

14 S. Liu, K. San Hui, K. N. Hui, J. M. Yun and K. H. Kim, J. Mater. Chem. A, 2016, 4, 8061-8071.

15 C. Xing, F. Musharavati, H. Li, E. Zalezhad, O. K. Hui, S. Bae and B.-Y. Cho, RSC Adv., 2017, 7, 38945-38950.

16 W.-Y. Ko, Y.-F. Chen, K.-M. Lu and K.-J. Lin, Sci. Rep., 2016, 6, 18887.

17 M. Li, S. Xu, C. Cherry, Y. Zhu, R. Huang, R. Qi, P. Yang, L. Wang and P. K. Chu, Electrochim. Acta, 2014, 149, 18-27.

18 D. Guo, L. Lai, A. Cao, H. Liu, S. Dou and J. Ma, RSC Adv., 2015, 5, 55856-55869.

19 R. Wang and X. Yan, Sci. Rep., 2014, 4, 3712.
20 Q. X. Xia, K. San Hui, K. N. Hui, S. D. Kim, J. H. Lim, S. Y. Choi, L. J. Zhang, R. S. Mane, J. M. Yun and K. H. Kim, J. Mater. Chem. A, 2015, 3, 22102-22117.

21 L. Zhang, K. Hui, K. Hui, X. Chen, R. Chen and H. Lee, Int. J. Hydrogen Energy, 2016, 41, 9443-9453.

22 L. Zhang, K. N. Hui, K. San Hui and H. Lee, J. Power Sources, 2016, 318, 76-85.

23 C. Guan, J. Liu, C. Cheng, H. Li, X. Li, W. Zhou, H. Zhang and H. J. Fan, Energy Environ. Sci., 2011, 4, 4496-4499.

24 H. Chen, T. N. Cong, W. Yang, C. Tan, Y. Li and Y. Ding, Prog. Nat. Sci., 2009, 19, 291-312.

25 Z. Yu, L. Tetard, L. Zhai and J. Thomas, Energy Environ. Sci., 2015, 8, 702-730. 